\title{
Work-Family Balance of Knowledge Workers In Poland
}

\author{
Aleksandra Wilczyńska \\ Universitat Oberta de Catalunya (UOC) \\ awilczynska@uoc.edu
}

DOI:10.5901/mjss.2014.v5n22p292

\begin{abstract}
The subject of managing both work and family spheres has drawn a lot of academic attention in the last few decades. Various models of work-family balance have been created. Yet, the most widely used, and perhaps the most feasible are models that measure balance by its absence. In the study, we use the work to family conflict model to investigate how work interrupts the family life. We focus on knowledge workers, as among this group the boundary between work and family spheres continue to be more and more blurry, especially with the presence of new information and communication technologies. In the research, we show how different working patterns and work attitudes influence family life. Additionally, we analyze the impact of usage of ICTs at home for professional reasons on familial harmony. In order to conduct the analysis we use the secondary data from the Social Diagnosis 2013 Project. The analysis is conducted on the group of knowledge workers (nkw=1, 457) and the rest of the workers (now=5, 955). The knowledge workers who used the Internet and e-mail at home for professional reasons were found to be more likely to face family problems than ones who did not use the new technologies in this manner. The relation between working hours and struggling with family problems has turned out to be non-linear and changing depending on the work environment perception. The results suggest that in general knowledge workers, who report work problems, have higher probability of struggling with problems in family than individuals who do not. The workers, who do not perceive their work as problematic, are more likely to have problems in family long very long hours. The individuals who work long hours are less likely to be subject to family problems, if they do not struggle with work-related problems..
\end{abstract}

Keywords: Work-family balance, knowledge workers, Poland

\section{Introduction}

Work family balance (WFB) has drawn a lot of attention in the last few decades and has been widely empirically analysed. Our society is viewed as increasingly rushed and work-centred. The view that the work and family spheres are separate realms is outdated and deeply flawed (Currie \& Eveline, 2010). These two spheres interact and intertwine between each other.

Various aggregated measures show that Poland falls behind the rest of Europe in terms of work-family balance. The average number of working hours in Poland is higher than in the European Union. Some groups of the workers in Poland, such as self-employed, work on average more than the persons from this group in most European countries (Eurofund, 2012). Also, Poles spend on average the least amount of hours in the week for personal care and leisure among all the European countries (OECD, 2014). Thus, it is noteworthy to establish a causal relationship between extended workdimension and diminishing and harmed family dimension in Polish families.

A group especially seen as exposed to obstructions in reaching a balance between the work and family life are the knowledge workers, the persons who "think for living" (Davenport, 2005). Among this group the boundary between work and family spheres continue to be even more and more blurry, especially with the presence of new information and communication technologies. As the new technologies emerged, companies started to give professionals greater time flexibility, making them responsible for managing their life schedule. Quantitative studies showed that these new arrangements, together with employer high expectations and workers' job insecurity resulted in increased time and effort invested in work (Moen, Lam, Ammons, \& Kelly, 2013; Perrons, 2003). The blurred boundaries are imposed by the working conditions of the knowledge workers, such as schedule and workplace flexibility, autonomy and accountability, teamwork, management by objectives and strict deadlines (Frenkel, Bendit, \& Kaplan, 2012).

The aim of the research is to show how different working patterns and work attitudes influence family life of knowledge workers. Extended working hours may affect persons who have a positive image of work differently than persons who have 
negative attitude towards work. Additionally, the impact of usage of ICTs at home for professional reasons on familial harmony is analyzed.

\section{Literature Review}

\section{Work-Family Balance: Definition and Models}

An intuitive definition of the term "work-life balance" is a point where a perfect harmony between work and private life is reached. However, this generic and vague definition does not suffice in a process of conceptualising work life balance for the means of empirical analysis. In fact, this raises more questions, for example what is the mentioned cut-off point of balance and how can it be captured? Another controversy associated with the subject of work/life balance is the specification of term "life" or "private life". Whereas "work" is, in most cases, a clearly defined dimension, "private life" is a conglomerate of different aspects of life such as family, leisure, health, etc. Even though the multidimensionality of the "life" part of the work-life balance concept is acknowledged, the research studies usually focus only its limited part, namely on the family aspect of life, e.g. Dyer, Mcdowell, \& Batnitzky (2011). Indeed family aspect seems to be the most prominent of all the dimensions and probably the easiest one to capture. However, for the sake of accuracy, the relation between work and family life should be denoted as work-family balance (WFB).

There are various models of WFB. The approaches most often taken by researchers measure either spill-over of work to family life or vice versa, or conflict between the two spheres (Guest, 2002). According to the spill-over model one world can influence the other in either positive or negative way. It can also combine both: work-to family life influence and family lifeto work influence, to establish the WFB (Pichler, 2008). The even more widely used approach is the conflict model, which assumes that extended activity in one sphere occurs at the cost of the other. The widely used definition of work-family balance complies with this model. It defines the term as a "satisfaction and good functioning at work and at home, with a minimum role of conflict" (Clark, 2000).

An interesting question associated with this issue is whether working long hours by choice is the situation of balance. Maybe it is worthwhile separating this category from the workers who work long hours as they feel obliged to do so. Peiperl \& Jones (2001) divide workers who work long hours into two categories: "workaholics" - ones who feel they get appropriate benefits (both tangible and intangible) from working more than average and "overworkers" - ones who do not feel the reward from their work is adequate.

Yet, work-family balance does not solely focus on the individual. It should also capture a family perspective. For instance "workaholics" may be satisfied with the time and attention they devote to both family and work spheres, yet it may affect how other family members share the time between these spheres. For this reason it is important to capture the other working family members' view on the work-family balance of the analysed individual.

Another potential doubt associated with this approach is the question whether measuring work family balance by conflict is appropriate. The literature sources suggest that individuals are more aware of work-family balance in the case of its absence (Guest, 2002). It can serve as a rationale for using this negative rather than positive indicator of work-family balance.

Another issue stressed in the literature is the fact that the dichotomy assumption in relation to the subject of work-life or even work-family balance is deeply flawed (Currie \& Eveline, 2010). The boundaries between work and private zone are being constantly blurred, and with the ubiquitous information and communication technologies this process is progressing even faster.

In general, the measures of work-family balance can be divided into objective and subjective ones. Among objective measures we can distinguish: normal weekly working hours, evening and weekend work, working overtime on short notice, free time, family roles and others. The subjective indicators usually measure self-reported balance, conflict or interference between the two spheres. Often the objective and subjective measures do not converge. Although a considerable correlation between working hours and self-reported work life (or family) balance is usually reported, it is not sufficiently high to use these two measures interchangeably. It brings a question about how well objective criteria can serve as indicators of subjective experience and whether we can rely on subjective accounts as valid indicators of balance without some evidence of others (Guest, 2002). A plausible solution to these issues would be to combine objective and subjective measures. This would allow the extraction of the group of "workaholics" who objectively work more than an average person, yet do not feel overwhelmed by this situation. Another technique to make the measure of work-family balance more robust 
is to use the reports not only from the individuals in question, but also accounts of persons from their closest environment. The ideal situation would be to have opinions of persons from both realms: a family member and a co-worker or a superior.

\section{Work-Family Balance in Poland}

The international accounts of work-life and work-family balance show that Poland falls behind in this area comparing to other European countries. Polish workers work on average 40.7 hours per week, 3.5 hours more than the European average (European Comission, 2013). Polish self-employed have the second longest working hours in Europe - 53h/week (Eurofund, 2012).

On the other hand, Polish workers spend significantly less time per day on leisure and personal care (i.e. eating, sleeping, socialising with friends and family, hobbies, games, etc.) than individuals in other European countries. Among OECD countries, Poland scores as the third lowest in this measure, after Turkey and Mexico (OECD, 2014). Also, a study on country clusters shows that individuals from Central and Eastern European countries (CEEs) spend on average the least time on domestic activities, including care activities (Eurofund, 2012).

These individual time-use measures suggest that Poland is a country, where the "work" component is prominent in worklife or work-family mix. There can be various reasons for this proportion, including individuals' preferences. However, when we compare these outcomes with some accounts from area of work organization, we can conclude that the work-life or work-family balance is hardly a priority among Polish labor market policies. For instance, the percentage of part-time jobs in Poland is considerably low - it constitutes $7.1 \%$ of total employment, whereas the EU average equals to $19.5 \%$. The part-time work can be viewed negatively, as it can be associated with exclusion from benefits and access to promotion. Nevertheless the possibility of working part-time is often a solution to manage work and family life. It is especially valuable for young parents, in particular mothers who often spend much more time on care activities than fathers (Eurofund, 2013). The recent results from European Working Conditions Survey show that there is a negative relation between average working time of women and female employment rate (Eurofund, 2012). It is worrying, as women who have exited the labour market upon entering the parenthood phase, tend to have lower well-being than the ones that remained in the job market. Also, these unfavorable conditions may hinder already low population growth.

Another issue is employers' induced job flexibility. Among all Polish workers, $31.6 \%$ work shifts. This percentage is among the highest in Europe. The EU average of shift workers as a percentage of all employment equals only to 18\% (European Comission, 2013). These atypical working patterns may have an adverse impact on employees' satisfaction from work-life balance (Eurofund, 2012). Additionally, Poland is characterized by highest in Europe percentage of temporary contracts (26.8\% compared to EU average of 13.8\%) (European Comission, 2013) and high job and employment insecurity (Dixon, Fullerton, \& Robertson, 2013). Although the unemployment rate (10.5\%) is not exceptionally high in comparison to other European countries, the unemployment among youth (15-24) is substantially higher than the OECD average $(26.5 \%$ and $16.2 \%$ in 2012 , respectively) (OECD, 2012). These factors may force, especially young people, to focus on professional life and neglect personal life.

\section{Knowledge Workers and ICT Usage}

In majority of the European countries, the amount of time spent at work increases together with earnings (Guest, 2002; $\mathrm{OECD}, 2011)$. Also, the probability of facing work-life balance problems grows together with the educational status (OECD, 2011; Pichler, 2008). One of the occupational groups that reports the most problems with WLB are managers and some groups of professionals (Ford \& Collinson, 2011; Guest, 2002; Shanafelt et al., 2012). This suggests that a cluster, which is exposed the most to the work-family conflict are highly educated workers, on well-paid top occupations. These characteristics are specific for knowledge workers. For them, the boundary between the two spheres are even more blurry, also because of the solutions brought by ICTs, that allow the workers to work from any place and communicate for work matters at any time, in other words be constantly bounded to the work milieu. The growing body of research shows that use of ICTs, even though may enhance the work performance, has significant adverse impact on the time devoted to family and the quality of this time (Boswell \& Olson-Buchanan, 2007; Currie \& Eveline, 2010). This study aims to shed a light on patterns of work-family balance among Polish knowledge workers and the factors impacting it, including the use of ICTs at home for work.

To analyze the work-family balance in the context of knowledge economy, it is crucial to establish a definition of a knowledge worker. However, a unique or straightforward definition of a knowledge worker does not exist. An occupational approach 
defines knowledge workers as "professional, managerial and technical people" (Drucker, 1993). Another way to define knowledge workers is to specify the content of their job, i.e. describe them as individuals whose work requires high levels of creativity, intellective skills and theoretical rather than purely contextual knowledge (Warhurst \& Thompson, 2006). However, this type of conceptualization is difficult to operationalize due to scarcity of the data about the actual character of the activities individuals carry out at work. For that reason the occupation-based approach, closer to Drucker's definition of knowledge workers, is often used to operationalize this concept. According to this classification knowledge workers are persons who work in the International Standard Classifiation of Occupations (ISCO) top three occupational classifications (managers, professionals, associate professionals) (International Labour Organization, 2010), have high level skills indicated by higher education or equivalent qualifications and perform tasks that require expert thinking and complex communication skills with the assistance of computers (Brinkley, 2006). The categories are not exclusive and may overlap. This occupation-based classification, as well as education-based classification is vulnerable to mistakes, as many of the workers that would be included in these categories usually would not be regarded as knowledge workers (i.e. managers of small firms, higher education graduates not working in the knowledge sector etc.). The way to minimise the error margin is to classify persons as knowledge workers if and only if they fulfil all three of the above-mentioned classification conditions.

The advantage of this way of using the occupation-based approach together with education-based approach is that it is a standard, used in most of the studies, as well as in the macro-level accounts. Thus, applying the three above-mentioned conditions in the study will allow its results to be comparable with outcomes of other studies of similar interest. This is why we have decided to use this standard for defining knowledge workers group.

\section{Methodology}

To analyze the work-family balance of knowledge workers, data from the Social Diagnosis 2013 (Rada Monitoringu Społecznego, 2013) are used. The dataset comprises a large number of cases and many relevant variables. However, the variables measuring work-family balance per se are not present in the dataset (also the time use variables measuring "family time" and variables measuring work-family interaction are missing). Yet, other widely available surveys that include the question about the work-family conflict, e.g. European Working Conditions Survey (EWCS), include a relatively small number of cases from Polish individuals with marginally small number of knowledge workers among them. For this reason another approach has been taken. Namely, a causal relationship between problems in family sphere and work sphere, time devoted to work and working from home with use of ICTs has been modeled.

The main objective of the research is to investigate if an extended work dimension may harm quality of family life. Particularly, the aim of the study is to test the following hypotheses:

H1 Family problems are more probable among workers who work long hours.

H2 The adverse impact of working long hours can be mitigated by the work perception (workaholics report less family problems than overworkers)

H3 Family problems are negatively influenced by the extensive use of ICTs at home for professional reasons.

As mentioned before, the work-family balance has been widely empirically analyzed. However, this study is run on a specific group, namely knowledge workers from Poland. So far the majority of the empirical research dealing with the work-family balance, especially in the context of knowledge economy, focused on the western countries. However, the knowledge sector in the CEEs, including Poland, is growing faster than in the western Europe (European Commission, 2012), thus the insight about the quality of life of this groups is also needed. The results for this group may be significantly different from the results obtained in the previous studies.

The usually taken approach is either to investigate the subjective perception of the hegemony of the work dimension, or to focus on objective measures, normally expressed by the number of hours spent on work. In this analysis the two approaches are combined to investigate the joint impact of subjective perception of the work sphere (i.e. self-reported work problems) and the time spent at work. The hypothesis $\mathrm{H} 2(\mathrm{H} 2$ : The adverse impact of working long hours can be moderated by the work perception) suggests that relation of long working hours on family life is ambiguous and changes depending on the work perception.

\section{Data Description}

\section{Social Diagnosis Project - Description of the Sample}


The analysis employs secondary data from the project Social Diagnosis 2013. (Rada Monitoringu Społecznego, 2013). The Social Diagnosis project, initiated in the year 2000 , is a diagnosis of the conditions and quality of life of the Poles. The dataset from year 2013 is the latest wave of the panel comprising seven waves.

The Social Diagnosis dataset contains vast amounts of data, coming from a large and representative sample. The data have been collected by Polish Central Statistical Office. The two-stage stratified sampling has been applied to find households that took part in the survey. Firstly, households have been stratified by voivodeships and then within voivodeships, by the size of agglomeration. The first stage sampling units were statistical regions (covering at least 250 apartments), and rural strata statistic circuits. In the second stage two flats were drawn systematically from a randomly ordered list of apartments, independently within each of the layers formed in the first stage of sampling. The appropriate weights, calculated with the use of set of variables (household size, voiveodeship, rural or urban area of living, gender and age group) are provided for the sample to make the it representative on the national level (Czapiński \& Panek, 2013). The weights are used throughout the presented analysis.

The research is focused on the specific subgroup of the population - knowledge workers. The group of the rest of the workers (excluding farmers) is used for comparison. The subgroup of interest has been separated from the whole sample in two steps. First, all the individuals that have a job were selected with help of four variables: Any paid work (or a helper without pay in the family business) performed during the last 7 days; An employee, a self-employed person or a helper without pay in the family business, but has temporarily not performed his/her work during last 7 days; Main source of income; Secondary source of income.

The first two variables determine if an individual performs any job (paid or unpaid). The latter two help restraining the dataset to the observations from respondents who gain any profit from their work activities. In the second stage knowledge workers are retrieved from the dataset. Knowledge workers are found by their educational level, ISCO occupational classification and by the usage of ICTs for work or educational purposes.

According to the used operationalization of the concept of knowledge worker and given the mentioned variable-setting criteria, the persons who belong to the group of interest are individuals with higher education (Bachelor's degree or higher), working in the top three occupational classifications (according to the ISCO classification) - Managers, Professionals or Associate Professionals and use information and communication technologies for work. With the described criteria 2, 160 (22.7\% of the all workers) knowledge workers were selected from the whole sample. The remaining $81.3 \%(7355)$ are the other workers.

Another condition set on the analyzed group is having a family. The family is understood as at least having a spouse or a partner. Consequently, the sample has been further reduced by excluding all the single workers. There are 1,503 cases of knowledge workers comprising given criteria. After reducing the incomplete cases, 1, 457 observations have been used. There were 5,955 of other workers remaining in the analysis

\section{Family Problems Index}

The family problem index is the dependent variable used in the causal model. The measure has been constructed using nine variables denoting self-reported issues associated with marriage, children and elderly relatives and one item related with the problems in marriage, reported by the partner. Namely, there are three variables denoting issues within marriage:

- $\quad$ Expectations of spouse so high, impossible to meet them;

- $\quad$ Spouse spends shared money in a careless manner;

- $\quad$ Problems of spouse worries and makes life harder.

The record of the latter has been also taken from the spouse of the individual. Another group of familial variables are ones associated with issues with children:

- Having to hear complaints about one's children from others;

- $\quad$ Financial costs due to action of children;

- $\quad$ Children ignore and reject one's help and advice;

- Feeling one loses control over/ influence on children.

The last group of family-related variables deals with the worries over elderly family members: 
- $\quad$ Feeling responsible for care and well-being of parents or elderly relatives;

- $\quad$ Feeling worried about physical and mental health of parents or elderly relatives

All of these indicators could take one of four levels:

1 Often;

2 Once or twice;

3 Never;

$4 \quad$ Not applicable.

The two latter levels have been equalized. Another solution would be to exclude from the analysis the individuals who do not have children. However, the family problems proxy is to measure a spectrum of family issues an individual is faced with. A person without children will not report any children-related problems, which means she or he is not struggling with as many problems as a person with children. For this reason a control measure - number of dependent children has been included in the model instead of restricting the sample to the couples with children.

The results for each individual within the family-related indicators have been summed up. Subsequently, a dichotomous variable "family problems" has been constructed, using mean of the mentioned sum as a cut-off point. As presented in Table 2, according to the binary indicator, $49.3 \%$ (nkw=744) of the knowledge workers and $41.1 \%$ (now=2472) of the other workers is struggling with family problems

\section{Work-Related Measures}

The study is focused on finding relation between the working dimension of an individual and the imbalance in familial life. Three different work-related measures have been used in the article: work-related problems, working time and the Internet use at home for professional reasons. To construct work-related problems variable, three indicators were used:

- $\quad$ Feeling that the job is tiresome, dirty and dangerous;

- Overload of duties hard to cope with;

- $\quad$ Being treated unjustly by other at work.

Similarly as in the family-related variables, measures could take one of four values: "Often"; "Once or twice"; "Never"; "Not applicable". Also in this case, level "Not applicable" has been aggregated together with "Never", as it is assumed that there are kinds of workers to whom the situations described by the variables do not apply. Also, in the case of the work problems indicators, the scores have been summed up. Afterwards, a binary measure has been constructed on the basis of the mean of the resulting sum. In the analyzed sample, $37.8 \%$ (now=2237) of the other workers and $32.0 \%$ ( $\mathrm{kkw}=460$ ) of the knowledge workers report work problems (Table 2).

To capture the joint impact of the long working hours and feelings about the work, a new variable has been derived. The variable "worker type" has four levels "Carefree workers" - workers who do not report problems at work and work o average 45 hours a week or less, "Frustrated workers" - workers who report problems at work and work on average 45 hours a week or less, "Workaholic" - workers who do not report problems at work and work on average more than 45 hours a week, and "Overworkers" - workers who report problems at work and work on average more than 45 hours a week, presented in Table 1. As this variable is used in the model, the variable work-related problems has been removed due to partial colinearity. The $15.5 \%$ of analyzed other workers are workaholics (now=942), $25.3 \%$ are frustrated workers (now=1500) and $12.5 \%$ are overworkers (now=737). Among the group of the knowledge worker, there are $11.2 \%$ workaholics (nkw=159), 8.4\% overworkers ( $n k w=116$ ) and $23.7 \%$ frustrated workers ( $n k w=344)$.

The measure denoting time spent on work is a continuous variable measuring how many hours on average a person works during a week. On average knowledge workers work slightly less than other workers ( $X k w=40, S D k w=10$ and $X o w=42$, SDow=11, respectively). Apart from that, a variable denoting managerial position has been included in the model as a control variable. It has been empirically proven that the persons especially exposed to work-related stress, burnout and work-family conflict are individuals with managerial position (Ford \& Collinson, 2011).

The last of the work-related variables is the use of the Internet and electronic mail at home for professional reasons. It is an ordered variable with three levels: "Never", "Ever" and "In the last week". Knowledge workers use new technologies to work at home out of their normal working hours much more often than the other workers. Almost $48 \%$ (nkw=687) of the 
respondents from the knowledge workers group stated they had used ICTs for professional reasons no longer than a week before the survey, whereas only $15 \%$ (now=772) of the other workers admitted to use these technologies as frequently.

Apart from the work-related variables, the control variables: sex, age and number of dependent children have been included in the model. Females in general suffer from higher work-to family conflict, as they usually are responsible for majority of the duties at home (Eurofund, 2013). The family problems variable includes problems with children, therefore the suspicion that having children would increase the risk of having family problems. Also, the age squared has been added to the model. There is some indication in the literature showing there is a u-shaped relation between age and well-being (Blanchflower \& Oswald, 2008) and directly between age and satisfaction from work-life balance (Allen et al., 2012). The distribution of persons with family problems across the age groups (Figure 1) in the used sample, suggest there is a bell-shaped relation between family problems and age.

\section{Model \& Results}

To test the hypotheses $\mathrm{H} 1-\mathrm{H} 3$, the two logistic models, separate for the groups of knowledge workers and other workers have been estimated. Both of them are statistically significant, according to the Omnibus test $(X 2$ ow $(12)=680.128, p<0.001$, $X 2 \mathrm{kw}(11)=278.803, p<0.00)$. The models results, together with the odds ratios $(O R)$ are presented in the Table 3.

The coefficients of the control variables have in general been consistent with the expectations. The female other workers turned out to be more exposed to the family problems than males (ORow $=1.459, p<0.001)$. In the case of knowledge workers, sex has turned out to be an insignificant factor in the model of familial problems. In the both groups, it has been shown that there is a bell-shaped relationship between family problems and age. In the both groups, having children increased the odds of having problems in family, by one fifth with every child in the case of other workers and by half in the case of knowledge workers (ORow=1.222, $p<0.001 ; \mathrm{ORkw}=1.508, p<0.001)$. The managerial position turned out to be an insignificant factor in both groups.

As suspected, using ICTs at home for professional reasons increases risk of family problems. In the case of knowledge workers, the higher the frequency, the greater were the odds of having family problems (ORkw=1.552, $p<0.001$, if individual ever used the Internet or e-mail at home for work reasons and ORkw=1.791, $p<0.001$, if he did so not earlier than one week prior to the survey). Also in the case of the other workers, using ICTs at home for work increases the risk of having problems in family, yet it does not grow linearly. The odds increase by half for other workers who have done so at least once (ORow=1.509, $p<0.001$ ). Yet, it grows by slightly less -0.369 (ORow=1.369, $p<0.001$ ) for persons who assumingly do it more frequently, comparing to the individuals who never use ICT at home for work. In the case of other workers, the model has shown that not using Internet slightly decreases the odds of having family problems, yet the result is not significant at the confidence level of $95 \%$ (ORow $=0.881, p=0.076$ ).

As hypothesized, not only working hours and having working problems, but also interaction between these two variables influences the family life. In the case of other workers, being "workaholic" is not significantly different from being the "carefree worker". In other words, the long working hours do not have an adverse impact on individuals from this group provided he or she does not has work problems. On the other hand, other workers who reported the work-related problems are at a significantly higher risk of facing family problems. Also, in this case, the difference between "frustrated workers" and "overworkers" is much bigger (ORow $=2.797, p<0.001$ and ORow $=4.061, p<0.001$, respectively). It shows that in the situation when the work is problematic for an individual, the long working hours strengthen the adverse impact on the family life.

In the case of knowledge workers, "workaholics" are at more risk of having family problems than "carefree workers" $(O W k w=2.871, p<0.001)$. It means that for this group, unlike for other workers, the prolonged working time has an adverse impact on the family life even when an individual does not report work problems. Also in this case, the impact decreases with the working time.

The "frustrated workers" and the "overworkers" have even higher odds of having problems in family life (ORkw=3.689, $p<0.001$ and $O R o w=3.785, p<0.001$, respectively). In comparison with the group of the other workers, the difference in odds between the "carefree workers" and the "frustrated workers" is much higher. On the other hand, unlike in the case of the other workers, among knowledge workers there is a small difference in the strength of the impact between the "frustrated" and the "overworkers". In fact, taking into account that the difference diminishes together with the working time $(\mathrm{ORkw}=0.976, p<0.001)$, in most situations, the group of frustrated knowledge workers is more likely to struggle with family problems. 


\section{Conclusions}

The hypothesis $\mathrm{H} 1$ (H1: Family problems are more probable among workers who work long hours) has not been confirmed. Especially in the case of the knowledge workers the influence of working time is ambiguous. Whereas the "workaholics" are more likely to struggle with familial problems than the "carefree workers", the "overworkers" are in most cases less likely to have family problems than "frustrated workers".

The second hypothesis ( $\mathrm{H} 2$ : The adverse impact of working long hours can be moderated by the work perception) has been confirmed. In both cases, persons with no work problems, who work the same number of hours, have less family problems. In the case of other workers, when the individuals do not report work problems, the long working hours do not increase the probability of having the work problems. In fact, the risk slightly decreases with each additional hour worked. In this group, "workaholics" - persons who work long hours, but assumedly do so from their own choice, are much less likely to experience family problems than the "overworkers" - assumedly the group, on whom the long working hours are imposed. In fact, in terms of family problems, there is no statistically significant difference between the "workaholics" and the "carefree workers". Thus, one can conclude, that working long by choice is a form of balancing between work and home. However, to draw a definite conclusion, the analysis should be complemented by the model focused solely on the reports of the significant others who are often affected by the working schedule of the "workaholics". Also in the case of the knowledge workers, the "workaholics" are much less likely to have family problems than the "overworkers".

In the both groups the third hypothesis (H3: Family problems are negatively influenced by the extensive use of ICTs at home for professional reasons.) has been confirmed. The result replicates outcomes of previous studies which show the possibility of working from any place, including home, brought by emergence of ICTs, may be advantageous for the job performance, but it also is likely to be harmful for the family life of an individual.

\section{References}

Allen, M., Schmidtchen, D., Rowles, M., Mao, Q., Paton, E., Young, J., ... Tait, D. (2012). State of the Service Report 2011-2012.

Blanchflower, D. G., \& Oswald, A. J. (2008). Is well-being U-shaped over the life cycle? Social science \& medicine (1982), 66(8), 1733-49.

Boswell, W. R., \& Olson-Buchanan, J. B. (2007). The Use of Communication Technologies After Hours: The Role of Work Attitudes and Work-Life Conflict. Journal of Management, 33(4), 592-610.

Brinkley, I. (2006). Defining the knowledge economy. Knowledge economy programme report. London: The work fundation.

Clark, S. C. (2000). Work/Family Border Theory: A New Theory of Work/Family Balance. Human Relations, 53(6), 747770.

Currie, J., \& Eveline, J. (2010). E-technology and work/life balance for academics with young children. Higher Education, 62(4), 533-550.

Czapiński, J., \& Panek, T. (Eds.). (2013). Social Diagnosis. Retrieved April 20, 2014 from

http://diagnoza.com/data/report/report_2013.pdf

Davenport, T. H. (2005). Thinking for a Living: How to Get Better Performances And Results from Knowledge Workers (p. 226). Harvard Business Press.

Dixon, J. C., Fullerton, a. S., \& Robertson, D. L. (2013). Cross-National Differences in Workers' Perceived Job, Labour Market, and Employment Insecurity in Europe: Empirical Tests and Theoretical Extensions. European Sociological

Review, 29(5), 1053-1067.

Drucker, P. F. (1993). Post-Capitalist Society. Oxford: Butterworth-Heinemann Limited.

Dyer, S., Mcdowell, L., \& Batnitzky, A. (2011). Migrant work, precarious work - life balance: what the experiences of migrant workers in the service sector in Greater London tell us about the adult worker model. Gender, Place \& Culture: A Journal of Feminist Geography, 18(October 2011), 685-700.

Eurofund. (2012). Working time and work - life balance in a life course perspective. Dublin.

Eurofund. (2013). Women, men and working conditions in Europe. Luxembourg.

European Comission. (2013). Labour Force Survey [Data file]. Retrieved May 13, 2014, from

http://epp.eurostat.ec.europa.eu/NavTree_prod/NodelnfoServices?lang=en\&nodeld=690 
European Commission. (2012). Eurostat. High-tech industry and knowledge-intensive services [Data file]. Retrieved June 17, 2014, from http://epp.eurostat.ec.europa.eu/portal/page/portal/statistics/search_database

Ford, J., \& Collinson, D. (2011). In search of the perfect manager? Work-life balance and managerial work. Work, Employment \& Society, 25(2), 257-273.

Frenkel, A., Bendit, E., \& Kaplan, S. (2012). The linkage between the lifestyle of knowledge-workers and their intrametropolitan residential choice: A clustering approach based on self-organizing maps. Computers, Environment and Urban Systems, 39, 151-161.

Guest, D. E. (2002). Perspectives on the Study of Work-life Balance. Social Science Information, 41(2), 255-279. International Labour Organization. (2010). ISCO - International Standard Classification of Occupations. Retrieved April 20, 2014, from http://www.ilo.org/public/english/bureau/stat/isco/

Locke, E. A. (1976). The nature and causes of job satisfaction. In Handbook of industrial and organizational psychology (pp. 1297-1349). Chicago.

Moen, P., Lam, J., Ammons, S., \& Kelly, E. L. (2013). Time Work by Overworked Professionals: Strategies in Response to the Stress of Higher Status. Work and occupations, 40(2), 79-114.

OECD. (2011). How's Life? Paris.

OECD. (2012). LFS by sex and age - indicators [Data file]. Retrieved May 13, 2014, from

http://stats.oecd.org/Index.aspx?DataSetCode=LFS_SEXAGE_I_R\#

OECD. (2014). Better Life Index. Poland. Retrieved May 12, 2014, from

http://www.oecdbetterlifeindex.org/countries/poland/

Peiperl, M., \& Jones, B. (2001). Workaholics and Overworkers. Productivity or Pathology? Group \& Organization Management, 26(3), 369-393.

Perrons, D. (2003). The New Economy and the Work-Life Balance: Conceptual Explorations and a Case Study of New Media. Gender, Work \& Organization, 10(1), 65-93.

Pichler, F. (2008). Determinants of Work-life Balance: Shortcomings in the Contemporary Measurement of WLB in Largescale Surveys. Social Indicators Research, 92(3), 449-469.

Rada Monitoringu Społecznego. (2013). Diagnoza Społeczna -zintegrowana baza danych [Data file]. Retrieved April 16, 2014, from http://diagnoza.com/

Shanafelt, T. D., Boone, S., Tan, L., Dyrbye, L. N., Sotile, W., Satele, D., ... Oreskovich, M. R. (2012). Burnout and satisfaction with work-life balance among US physicians relative to the general US population. Archives of internal medicine, 172(18), 1377-85.

Warhurst, C., \& Thompson, P. (2006). Mapping knowledge in work: proxies or practices? Work, Employment \& Society, 20(4), 787-800.

\section{Figures}

Fig 1 The Percentage of the Persons with Family Problems Among Six Age Groups (Separately For Knowledge Workers and Other Workers)

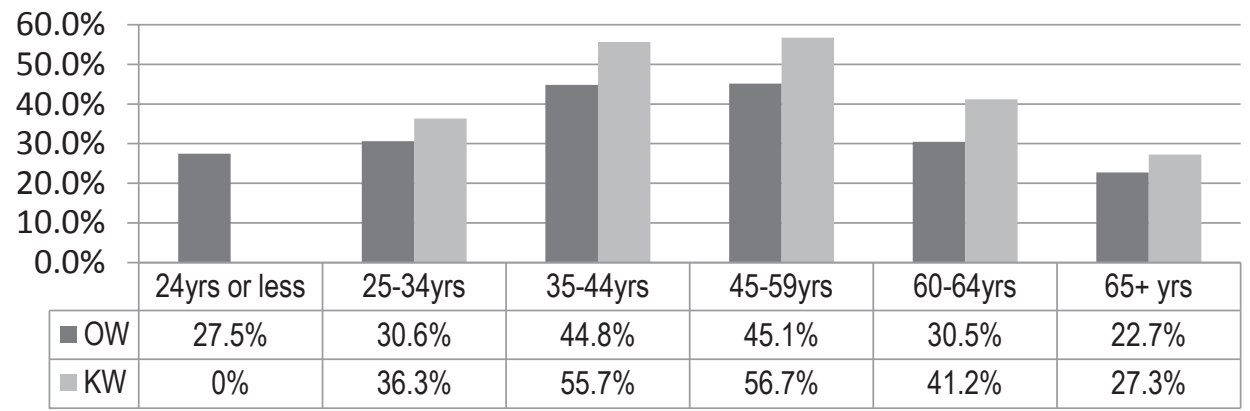




\section{Tables}

Table 1. Presentation of the Variable "Worker Type"

\begin{tabular}{|c|c|c|}
\hline & Working Time & \\
\hline & $45 \mathrm{~h}$ or less & More than $45 \mathrm{~h}$ \\
\hline No Work Problems & "Carefree" workers & Workaholics \\
\hline Work Problems & "Frustrated" workers & Overworkers \\
\hline
\end{tabular}

Table 2. Characteristics of the Sample Separately For Knowledge Workers and Other Workers.

\begin{tabular}{|c|c|c|c|c|c|c|c|c|c|}
\hline & & \multicolumn{4}{|c|}{ Other worker } & \multicolumn{4}{|c|}{ Knowledge worker } \\
\hline & & $x$ & SD & $\mathrm{N}$ & Col \% & $x$ & SD & $\mathrm{N}$ & Col $\%$ \\
\hline$\overline{\mathrm{AGE}}$ & & 44 & 10 & & & 40 & 9 & & \\
\hline CHILDREN & & 1.20 & 1.11 & & & 1.15 & .91 & & \\
\hline W_HOURS & & 42 & 11 & & & 40 & 10 & & \\
\hline \multirow{2}{*}{ SEX } & MALE & & & 3412 & $59.8 \%$ & & & 559 & $41.3 \%$ \\
\hline & FEMALE & & & 2543 & $40.2 \%$ & & & 898 & $58.7 \%$ \\
\hline MANAGER & & & & 488 & $9.2 \%$ & & & 384 & $25.9 \%$ \\
\hline W_PROBLEMS & & & & 2237 & $37.8 \%$ & & & 460 & $32.0 \%$ \\
\hline F_PROBLEMS & & & & 2472 & $41.1 \%$ & & & 744 & $49.3 \%$ \\
\hline $\begin{array}{l}\text { F_PROBLEMS } \\
\text { (SPOUSE) }\end{array}$ & & & & 2728 & $46.2 \%$ & & & 688 & $45.6 \%$ \\
\hline \multirow{4}{*}{ WORKER_TYPE } & CAREFREE & & & 2776 & $46.7 \%$ & & & 838 & $56.8 \%$ \\
\hline & WORKAHOLIC & & & 942 & $15.5 \%$ & & & 159 & $11.2 \%$ \\
\hline & FRUSTRATED & & & 1500 & $25.3 \%$ & & & 344 & $23.7 \%$ \\
\hline & OVERWORKER & & & 737 & $12.5 \%$ & & & 116 & $8.4 \%$ \\
\hline \multirow{4}{*}{ ICT_HOME } & NEVER & & & 2205 & $38.2 \%$ & & & 241 & $13.8 \%$ \\
\hline & EVER & & & 907 & $18.4 \%$ & & & 529 & $38.5 \%$ \\
\hline & LAST WEEK & & & 772 & $15.0 \%$ & & & 687 & $47.7 \%$ \\
\hline & NO INTERNET & & & 2071 & $28.4 \%$ & & & 0 & $0.0 \%$ \\
\hline
\end{tabular}

$\mathrm{X}$ - mean; SD - standard deviation;

$\mathrm{N}$ - unweighted count; Col \%, - column percentage (weighted).

Table 3. Results of The Logit Models For The Predictors of Self-Reported and Spouse-Reported Family Problems (Results for Knowledge Workers and Other Workers) 


\begin{tabular}{|c|c|c|c|c|c|c|}
\hline & Est. & SE & OR & Est. & SE & OR \\
\hline FEMALE & $0.378^{* * *}$ & 0.058 & 1.459 & 0.135 & 0.106 & 1.145 \\
\hline AGE & $0.222^{\star \star \star}$ & 0.026 & 1.261 & $0.204^{\star \star *}$ & 0.047 & 1.226 \\
\hline AGE2 & $-0.002^{\star * *}$ & 0.000 & 0.998 & $-0.002^{\star * *}$ & 0.001 & 0.998 \\
\hline CHILDREN & $0.201^{* * *}$ & 0.028 & 1.222 & $0.411^{* * *}$ & 0.062 & 1.508 \\
\hline W_HOURS & $-0.011^{* * *}$ & 0.004 & 0.989 & $-0.015^{\star * *}$ & 0.118 & 0.976 \\
\hline MANAGER & 0.024 & 0.097 & 1.025 & -0.024 & 0.118 & 0.980 \\
\hline ICT EVER & $0.411^{* * *}$ & 0.079 & 1.509 & $0.439^{* * *}$ & 0.159 & 1.552 \\
\hline ICT LAST WEEK & $0.314^{* * *}$ & 0.084 & 1.369 & $0.583^{\star \star *}$ & 0.157 & 1.791 \\
\hline NO INERNET & $-0.126^{*}$ & 0.071 & 0.881 & & & \\
\hline WORKAHOLIC & 0.143 & 0.103 & 1.154 & $1.055^{\star * *}$ & 0.194 & 2.871 \\
\hline FRUSTRATED & $1.028^{* * *}$ & 0.067 & 2.797 & $1.305^{\star \star \star}$ & 0.124 & 3.689 \\
\hline OVEROWORKER & $1.402^{\star \star *}$ & 0.108 & 4.061 & $1.331^{\star \star *}$ & 0.216 & 3.785 \\
\hline Constant & $-6.307^{\star * *}$ & 0.560 & 0.002 & $-5.780^{\star * *}$ & 1.001 & 0.003 \\
\hline $\mathrm{N}$ & 5,955 & & & 1,457 & & \\
\hline Log Likelihood & $7,715.265$ & & & $2, .372 .472$ & & \\
\hline Akaike Inf. Crit. & 4588.506 & & & $2,252.500$ & & \\
\hline
\end{tabular}

${ }^{*} p<0.1 ;{ }^{* *} p<0.05 ;{ }^{* * *} p<0.01$

n.s. - non-significant; Est. - estimate; SE - standard error; OR - odds ratio 